\title{
Professional development through formative evaluation
}

\author{
Rejoice Nsibande $^{1}$ and James Garraway ${ }^{2}$ \\ University of Pretoria, South Africa \\ Cape Peninsula University of Technology, South Africa
}

Keywords: professional development, reflection, formative evaluation, communities of practice, identity.

Formative evaluation and its associated methodology of reflection on practice are used extensively in academic staff development. In reflecting on formative evaluation processes in both more traditional and newer programmes conducted at a university of technology a number of variables reported in the literature were observed to have influenced academic staff members' ability to reflect and change practice. Drawing on illustrative cases, this paper argues that explicit attention needs to be given to additional variables concerned with the nature of the knowledge being taught, academic identity and the availability of a community of educational practitioners if academic developers are to foster critical reflection as an essential element of formative evaluation and productive change in practice.

\section{Introduction}

In this paper we reflect on a project which attempted to use 'formative evaluation' as a tool to improve teaching and learning. Higher education in South Africa underperforms generally across all race groups when compared to similar developing countries. What is even more concerning is that the already low graduation rates are racially skewed, with, for example, white engineering students being twice as likely to graduate as compared to African students (Scott, Hendry \& Yeld, 2007).

The standard of teaching and the ability to change practices to meet the needs of new students has been identified as a significant causal factor in low graduation rates, though poverty and inadequate preparation also play a role (Letseka, Breier, \& Visser, 2009; Scott et al., 2007). Using formative evaluation to improve teaching and learning is thus of great importance in achieving educational transformation in South Africa.

Following McAlpine, Weston, Berthiaume, Fairbank-Roch, and Owen, (2004) we understand formative evaluation to involve lecturers in standing back from their classroom experiences to some extent in order to assess what is happening and, where necessary, to come up with new practices. Formative evaluation draws strongly from

\footnotetext{
${ }^{1}$ rejoice.nsibande@up.ac.za

2 garrawayj@cput.ac.za
} 
the concept of the 'reflective practitioner' (Boud, 1998; Cochran-Smith \& Lytle, 1999; Schön, 1987) as a model for academic development. Despite some identifiable shortcomings, Schön's approaches and the concept of the reflective practitioner in general have been enthusiastically taken up in higher education research and development studies (Boud \& Walker, 1998; Brockbank \& McGill, 1998).

The issue of lecturers' knowledge has been referred to in the literature on professional reflection. Where either pedagogical or field knowledge is under-developed, then lecturers may experience difficulty in productively using reflection to improve teaching (McAlpine et al., 2004; McAlpine \& Weston, 2000). The situation may be exacerbated, we suggest, in new fields of study in universities of technology where there are neither well developed knowledge structures nor established communities of educational practitioners.

\section{Reflection as strategy for professional development}

Schön $(1987,1995)$ has been a major proponent of reflection as a tool for professional development. Experience alone is not enough. For experience to become learning and knowledge it needs to be stopped in time, described (making the tacit explicit) analysed, and considered at some length. In analysis and consideration the experience shifts from the specific instance in which it occurred to a more general realm of knowing (Criticos, 1993; Schön, 1987).

Boud, Keogh and Walker (1985) attempted to articulate the process of learning through reflection on experience in a way that was both simple enough to use and adaptable to a variety of contexts. As with Schön, the process described was first one of 'surfacing' a past event through describing it as fully as possible. This was then followed by reflection on the issues and feelings related to the event, with particular attention being paid to what could obstruct and what could support further reflection. The third stage of the reflective process involved the integration of the first two stages with other experiences and learning, and the creation of a personalised narrative that made sense in terms of the individual's practice.

More recent work on reflection has been critical of these earlier, more simplified process models for underplaying the role of the context in which reflection occurs, and some of the complexities involved in performing reflection. These critical examinations revealed first, that more attention needed to be given to the intent of the individual reflecting (Boud and Walker, 1993). McAlpine and Weston (2000), for example, stress the importance of staff's motivation to reflect on and improve practice, especially where the problem is perceived to lie outside of their influence (for example class size or student profile).

Second, barriers to reflection and learning had not been adequately explored as the focus had been more on supporting positive feelings to reflection. Barriers could be internal, related to the individual's feelings, abilities and dispositions or external, related to the institution, its values, rules and reward systems (though Boud and Walker (1993) recognised that internal barriers may have external causes). Reflection to improve and transform practice is both a very personal and challenging practice, potentially opening up the practitioner to critique. The activity of reflecting on teaching may thus 'leak' into larger areas of concern which may be directed at the researcher. As Boud and Walker (1998: 194) describe it, 'reflective activities may 
lead to great personal distress,' an example of an internal barrier to reflection and learning. Boud (2001) and McAlpine and Weston (2000) stress that reflection needs to occur within a protected space where teachers can address their concerns without fear of consequence. Where reflective practices are situated by the lecturer within a quality discourse of policing rather than through a discourse of learning and support (Boughey, 2001) teachers may only engage superficially or even resist reflective activities (Boud, 2001).

Third, there needs to be attention to the nature of event reflected on; what was significant about the event, or what made it 'noticeable' to begin with (Boud \& Walker, 1998, p. 76). Academic staff may lack the knowledge needed to pick up teaching and learning events that may warrant reflection (McAlpine \& Weston, 2000). Thus there needs to be more focus on reflection-in-action (Schön, 1987). Furthermore, changing teaching in response to these stimuli (reflection-on-action) would also require sufficient knowledge of the field and of pedagogy, or pedagogic content knowledge (McAlpine \& Weston, 2000; Shulman, 1987).

One aspect of limited knowledge of the field and pedagogy may be that the process of reflection is self-confirming rather than critical (Brockbank \& McGill, 1998). The authors suggest this can be avoided through asking teachers not only to reflect on action but also to examine and challenge their firmly held beliefs. Such a process may also be instrumental in moving lecturers beyond simply changing an element of practice towards developing more advanced thinking in which new hypothesises or knowledge constructs may emerge (McAlpine et al., 2004).

\section{The problem of knowledge in reflection}

Though knowledge is acknowledged in the literature as an enabling factor for productive reflection (for example, McAlpine et al., 2004), not much has been said about the different types of university knowledge or of their socio-cultural bases. The nature of university knowledge fields has traditionally been described using Becher and Trowler's (2001) field dimensions of hard and soft and pure and applied. A field such as Engineering would fall into the hard applied category, Education and Business Studies into the soft applied category, and pure Physics and History would be examples of hard and soft pure fields respectively. The fields are not only constituted by the type of knowledge they include, but also by the typical shared values and practices within that field. Fields thus have both knowledge and a social base.

The applied fields are what Bernstein (2000) describes as 'regions' in that they are often derived and selectively constructed from a number of pure fields. Not everything in the pure fields would be relevant. Exactly what is chosen from each pure field would be influenced by the knowledge needed and typical practices of particular professions such that the resultant mix has an outward looking logic to its curriculum construction (Barnett, 2006).

Some applied fields, such as Engineering and Education, have a long history in universities. Lecturers in these fields have developed a strong community of practitioners who share and develop their knowledge bases and teaching practices, often through dedicated teaching journals and conferences. A sense of identity as a 
professional educator is potentially quite strong. There is also a large corpus of knowledge about disciplines and practices and debate to draw on in designing and implementing the curriculum. There are thus 'robust' tools and opportunity for innovation in the curriculum (Muller, 2008, p. 18).

Newer academic fields derived from new 'fourth generation professions' (Muller, 2008), for example in the hospitality or certain business and information related work, may not exhibit such a strong community of practitioners orientated around stable but developing knowledge bases and teaching practices. Practitioners in these fields would be less likely to hold strong professional academic identities. Consequently, a practitioner's identity may be more outward looking (focussing on work practices), and the underlying knowledge to critique and be innovative with curriculum knowledge and practice is likely to be under-developed (Beck \& Young, 2005; Muller, 2008).

Shulman, (1987) makes a similar point with his concept of pedagogical content knowledge. This involves understanding the underlying theory, concepts and rules of the discipline rather than just its more superficial procedural form. Where this knowledge is weak then lecturers may lack the resources to adapt their teaching to changing circumstances or to the needs of their students.

\section{The context of the evaluation project}

The project was conducted in a University of Technology in South Africa. Such universities, being concerned with the delivery of tertiary vocational knowledge, place much emphasis on lecturers' workplace knowledge and experience and less on their academic or pedagogical knowledge. The teaching fields are thus both applied and outward looking, though the degree of robustness in terms of their knowledge base and pedagogy may differ.

The quality of teaching at faculty level has been predominately supported by what is referred to as 'marks reviews'. Here, lecturers whose students have underachieved (usually, average course end mark is less than 60\%) in a subject are called to task by the Head of Department (HoD) and asked to explain student's poor results and to come up with ways to improve student marks. The HoD then presents this information to the marks review committee consisting of the Dean, Deputy Dean, Quality Manager, other HoDs and representatives of the Academic Development Unit. The brief of the committee is then to evaluate an academic staff member's intended solutions to improve practice. As members of the Academic Development Unit listening to these presentations, we were struck by their shallowness and lack of academic rigour, with staff usually laying the blame on blaming students' underpreparedness or poor attitude to learning. There was no serious critique or challenge to current practices.

To address these observations, a second phase of the marks review was designed to involve lecturers in engaging reflectively with their teaching.

\section{Methods}

Three subject evaluations derived from the marks review process and one voluntary evaluation requested by the subject lecturer (Engineering 2) were conducted by the authors in 2007/8. We first had meetings with staff who taught the subject being 
evaluated to ascertain issues contributing to poor performance of students. The purpose of this consultation was to facilitate a process where the evaluation addressed issues that teaching staff saw as crucial rather than issues of interest to the evaluators (Patton, 2002). In addition, we were careful to present the project as one of enhancement rather the surveillance, and to indicate to staff the benefits that could accrue to them from the evaluation project. Following these same principles, students were also interviewed. In the initial discussions with lecturers and students we made it clear how the data collected in the process would be used. For instance, they were assured that information collected will be treated as confidential and used for writing reports as per HoDs request but where there is potential, could be published academically to promote debate on the nature of academic development work. There was no objection to such as long as their identities were protected.

We then observed and recorded lectures presented by each of the lecturers. Videorecorded lessons were used in two ways. Firstly, the evaluators reviewed them to get a 'feel' of how students were taught and what they were doing during the teaching. Secondly, they were used as a tool to stimulate reflective discussions between the evaluator and the lecturers, a form of 'professional dialogue' (Nsibande, 2007). Lecturers were asked to point out what they were doing at particular points and why they were doing it this way. The review was done individually and in an unstructured way to allow engagement with issues relevant to each lesson (Henning, 1999). In addition, materials (textbooks, notes, etc.) were also examined for their usability, particularly if this was an issue raised by students or staff in the interviews.

Interviews, discussions and observations of staff in the classroom provided us with data on how the subject is typically taught as well as staff responses to formative evaluation. We were also able to construe the nature of the subject and something about the lecturer's background. The data was then written up in the form of vignettes for each of the formative evaluations conducted, which in turn allowed us to compare the different evaluations.

The data for each of the formative evaluations conducted was written up in the form of anonymous vignettes, which allowed us to compare the different evaluations without revealing from which department they were derived. The vignettes were developed from actual formative evaluation reports submitted to the staff interviewed and to the HoDs. Though the reports themselves were openly discussed, the vignettes represent more of the academic developers' theoretically-derived views on the underlying issues and tensions in the reports.

\section{Four formative evaluation vignettes}

\section{Engineering 1}

The field is a developed field, strongly aligned to Physics and Mathematics. There is a strong local community of educators with a journal published twice yearly and a national conference held every two years. The lecturer has come from a science education schooling background and is not an engineer. The classes are approximately 70 in size, with students at desks in rows. The lecturer does examples of calculations on the whiteboard, often illustrating them with practical examples, and students attempt to solve similar problems on their own or in groups. There is a textbook to 
support students in their learning. The lecturer has been asked by the HoD to meet with us to discuss possible changes to teaching practices, as students are performing poorly in the final exams.

The lecturer is unhappy with the evaluation process and feels that the evaluation is targeting their teaching whereas there are other worse or needier teachers who are not being evaluated. The lecturer also felt that much of the problem lies with students' under-preparedness and poor commitment to work (a common complaint) rather than anything attributable to classroom practices.

In general students are very positive about their lecturer, though some areas for development were revealed. In one instance we identified strong support for formative peer marking as a method to provide a richer learning experience for students. The staff member's initial response was negative as this suggestion had already been tried and had not been very successful. The staff member later came around to the idea of peer marking and supported its development but only after becoming aware that what was being proposed was quite different from his/her original understanding.

\section{Engineering 2}

As above, there is strong discipline base in Physics but also including Chemistry, and there is a well developed pedagogic field. The lecturer is ex-industry but has taught for many years and engaged with peers on issues of teaching and learning (through workshops and conference attendance, for example). The class is in the same format as Engineering 1 but the lecturer attempts to develop a more active, conceptual development focus. Again, there is a textbook and many available materials from the internet to support student learning.

The HoD is aware that students are performing poorly and that they are not happy with their lecturer, but the lecturer rather than the HoD has approached us for an evaluation (if he had not done so he would have anyway been asked to do so). In discussing issues raised by students with the lecturer, we were worried that student comments might appear to be very harsh.

However, while other lecturers tended to dwell on how students were a problem, this lecturer did not avoid looking critically at his/her own practices. The lecturer had attempted more interactive, inquiry-based lectures to promote learning. But students were critical of the lecturer not seeming to have a clear structure to his lecture, and going off in different directions in response to student queries, or with illustrative metaphors that students found were off the point, often resulting in a failure to finish the lecture on time. In addition students were often asked to discuss amongst themselves which took time. The lecturer acknowledged that his class was too 'freeflowing' and that more structure in the form of a 'road map' was necessary and connections across lectures were necessary.

\section{Management}

The field is relatively new unlike the more traditional Engineering field. The subject is concerned with aspects of production organisation, management and quality. The subject is largely practice-based and strongly influenced by expectations from industry that the university produce graduates who are able to execute tasks on the production floor. In other words it is quite procedurally focussed. The key disciplinary 
bases within the subject are quantitative literacy and organisational studies, which are themselves regions derived from other subject and experiential bases, and are thus somewhat ill-defined. There are textbooks available but lecturers prefer to write their own notes based on their experiences in industry. There is no evidence of a community of practitioners concerned with developing knowledge and practice in the field. This field does not have a strong academic tradition with few or any students proceeding beyond diploma and degree level. The classes of 60 or so students are conducted in a banked lecture theatre. The lecturer demonstrates calculations on the whiteboard, then students do their own calculations individually, offering answers and receiving feedback.

The lecturer had been requested by the HoD to meet with us and to be evaluated. The evaluation process was one which they perceived as unfairly targeting him/her leading to frequent extreme emotional discomfort. In discussion, staff felt they were trying to teach as best as possible, but that the students were the problem and this was simply not being acknowledged by either their HoD or by us as evaluators. In response to suggestions as to how they might make the classroom more active and conceptually demanding, we found that the staff member believed that $\mathrm{s} /$ he was already doing that and that no new changes were necessary, though this self-assessment was inconsistent with our observations of teaching. Generally we found the lecturer to be protective about current practices and hence resistant to change.

\section{Health}

The health subjects were situated within a well established health education field, though there was no evidence of local education conferences or journals or a strong, local community of practitioners. The community, rather, seemed to be at some distance in North America and Europe. The subjects in question were applied biology and human physiology. There is a very comprehensive textbook that is formatted more like a resource manual than a guide to learning. It is very large and unwieldy (we weighed it at $5 \mathrm{~kg}$ ). The initiative to evaluate the subjects had come from both the HoD and staff themselves. Staff had already tried to do some evaluation of their own through distributing a questionnaire to students, but were at a loss as to how to address the problem of poorly performing students. Hence it was requested that we perform an evaluation.

The lecturers were all health professionals who had been teaching for extended periods. In this particular profession, teaching staff have to complete a post-graduate teaching certificate to teach at university.

Staff found it difficult to engage with different approaches to teaching and, anyway, did not see any reason to change their own practices as, in their own words 'they had been teaching like this for years'. The bulk of the problems experienced by staff were ascribed to the poor quality and attitudes of students which, staff felt, were forced on them by government and institutional policy. The evaluators were sometimes treated with hostility; as with Engineering 1 and management, being evaluated was experienced by staff as an emotive and seemingly threatening experience. 


\section{Discussion of Vignettes}

In reflecting on the vignettes, the sense that engaging in reflective processes about problems with teaching may lead to some form of censure is evident in all but Engineering 2's perceptions; lecturers experience the evaluation process as quite distressing. This finding links back to Boud's (2001) observation of the need for a protected space for teaching development, away from the eyes of managers. In using the institutional review mechanism as a starting point for formative evaluation, we may have fallen into the trap raised in Sue Clegg's Think-Piece (2008, p. 3) that Academic Development practitioners 'can find themselves positioned precariously between senior academic management and academic staff.' Rather than being understood by staff as an opportunity for self-development the evaluation was seen as potentially censorious in that it revealed staff's weaknesses to management. This in part explains why Engineering 2's responses to the reflective evaluation were so positive. In this case, participation was voluntary. However, we cannot ignore the institutional marks review process and the need to improve on this by making it more reflective and developmental. One of the challenges for academic developers is the importance of appreciating the context in which reflection on teaching is undertaken.

A second dimension of the context for reflection is the national higher education milieu. In three of the vignettes (Engineering 1, management and health) lecturers perceive that it is not so much their practices which are at fault but rather that students are un-prepared for university study, and that this is not adequately acknowledged. Thus there may be scant motivation for engaging reflectively to improve practices. Though 'massification' and with it the perception of an increasingly un-prepared new student body is a world-wide phenomenon, it has a particular resonance in South Africa where racial transformation is a major issue.

A third dimension of context for reflection is personal. Staff in these three vignettes also indicate a certain resistance to new ideas, including the perspective that reflection tends to be self-confirming (Brockbank \& McGill, 1998); for example, staff talk of always having taught this way, of always engaging students or of already having tried something innovative which did not work (e.g., peer marking). In the latter example there is some evidence of a staff member eventually re-thinking their approach. In contrast, in the Engineering 2 vignette, the staff member responds most positively to critique, and is able to come up with ideas for changing practices.

One of the challenges for this paper is to try to explain the influence of these contextual variables on the ability of academic staff to reflect on and to change practices. Context may be the most obvious and common sense explanation concerning staff's willingness to engage in reflection to begin with, as illustrated in the single vignette where participation was voluntary (Engineering 2). However, the vignettes themselves suggest at least one other barrier to staff's ability to reflect and implement change: that of disciplinary knowledge and the lecturers positioning in communities of educational practitioners.

The two Engineering and the Health subject areas have strong and developed disciplinary bases derived from well-established subjects (for example, Physics and Biology). The variation in staff responses to critiques could in part be ascribed to their different levels of membership in their communities of teaching practitioners. The Engineering 1 lecturer does not appear to have developed a strong professional 
identity in the field, though this is in part counter-balanced by the lecturer's general pedagogic knowledge. However, their lack of robust tools for curriculum innovation in this particular teaching context (Muller, 2008) may reflect an absence of professional identity with colleagues with common discipline and teaching interests. . A similar observation can be made about the health lecturers.

The lecturer in Engineering 2 has the strongest and most developed membership (and hence academic identity) and this, along with the lecture's seeking to be evaluated rather than being required to do so, is an enabling factor in being able to reflect on and adapt practice. Even though the discussion did not go deeply into the nature of the subject the lecturer still opened up to critically look into the processes put in place to encourage and support students' learning. This knowledge of processes provided the lecturer with a lens to view practice and appreciate what works and what needs to be modified.

The management course, on the other hand, has the weakest disciplinary bases, with a focus on knowing how to do something rather than knowledge about why things are done. In addition, this vignette also demonstrated the weakest community of practitioners. A focus on knowledge-how is related to both the background of the management lecturers and the strong influence of industry on the course. It tends towards a more rigidly structured teaching and learning methodology rather than a more flexible approach based on both knowledge-how and 'knowledge-why' (Muller, 2008 , p. 18). It does not have to be this way, however. Knowledge-how becomes knowledge-why when it is, for example, compared across different work contexts or across different historical periods. In doing so, the lecturers engage in both academic and pedagogic social practices that could enhance their sense of membership in a community, their academic identities, and their propensity to welcome and respond to change.

\section{Conclusions}

Our aim in this paper has been to expand the notion of context in reflection on teaching practice as originally highlighted by authors such as Boud and Walker (1993) and McAlpine and Westorn (2001) to include the robustness of the academic field and academic identity within various professional fields. Where the identity of the practitioner is strongly developed then they are more likely, given that other enabling conditions prevail, to conduct meaningful reflection and implement change. There are implications for new fields or regions in universities of technology where such a specialised identity and participation in communities of practitioners may be only weakly developed, and this in turn has implications for educational transformation.

The implications are that new fields may need more reading and writing, both in terms of what they are centrally concerned with and how they are best taught. This 'academic drift' is necessary in order to improve teaching and learning in the field as it provides the basis, through reflection, for change and development. Where the focus is on instrumentality then 'the knowledge that permits alternative possibilities to be thought' may be effectively silenced (Beck \& Young, 2005, p. 193). However, more research about teaching and learning is needed within these new fields, for example in 
tourism and complementary medicine, before more robust generalisations can be made.

A fundamental contradiction must be acknowledged here. Where practices have been developed and refined over the years in the older regions (such as Engineering) then there may be strong adherence to the 'community' and a resistance to change. And this may particularly be the case where lecturers are required to respond to the need for transformation in South Africa. For example, a recurrent theme in reflection on teaching is that it is the students who are to blame for their lack of learning. Newer regions, then, may be more amenable to change as they are less set in their ways. The problem, however, of the means to effect change still remains.

\section{Notes on Contributors}

Rejoice Nsibande is an education consultant for Faculty of Law at the University of Pretoria. Her responsibilities are to support academic staff in their professional development. This involves supporting academic staff in designing curriculum and encouraging them to develop best practices in teaching, learning, and assessment in higher education through customised workshops and individual consultation.

James Garraway is Head of the Department of Extended Curriculum Programmes at Cape Peninsula University of Technology. His work involves supporting academic staff in designing curriculum for these programmes and in developing their competencies with regard to teaching, learning and assessment in higher education.

\section{References}

Barnett, M. (2006). Vocational knowledge and vocational pedagogy. In Young. M. and Gamble, J. (Eds), Knowledge, Curriculum and Qualifications for South African Further Education (pp. 143-157). Cape Town: HSRC Press.

Becher, T. \& Trowler, P., (2001). Academic Tribes and Territories (Second Edition). Buckingham, UK: SRHE and Open University Press.

Beck, J., \& Young, M.F.D. (2005). The assault on the professions and the restructuring of academic professional identities: A Bernsteinian analysis. British Journal of the Sociology of Education, 26 (2):183-197.

Bernstein, B. (2000). Pedagogy, Symbolic Control and Identity (revised edition). Lanham, MD: Rowman and Littlefield.

Boud, D. (2001). Using journal writing to enhance reflective practice. In English, L., and Gillen, A. (Eds), Promoting Journal Writing in Adult Education. New Directions in Adult and Continuing Education No. 90, (pp. 9-18). San Francisco: Jossey Bass.

Boud, D., Keogh, R., \& Walker, D. (1985). Promoting reflection in learning: A model. In Boud, D., Keogh., R and Walker, D (Eds), Reflection: Turning Experience into Learning (pp. 18-40). London: Coggan. 
Boud, D. \& Walker, D. (1993). Barriers to reflection on experience. In Boud, D., Cohen, R., and Walker, D. (Eds), Using Experience for Learning (pp. 73-86). Buckingham, UK: SRHE.

Boud, D. \& Walker, D. (1998). Promoting Reflection in Professional Courses: The Challenge of Context. Studies in Higher Education, 23 (2): 191-206.

Boughey, C. (2001). Evaluation as a means of assuring quality in teaching and learning: Policing or development? In Otaala, B. and Opali, F. (Eds.), Teach your Very Best: Selected Proceedings of a Regional Conference for Staff from Tertiary Institutions from SADCC Countries (pp. 18-29). Safari Court and Conference Centre, Windhoek, Namibia, 1-3 October, 2001.

Brockbank, A., \& McGill, I. (1998). Facilitating Reflective Learning in Higher Education. Buckingham, UK: SRHE.

Clegg, S. (2008). Forms of knowing and academic development practice. Think Piece - Professional /Academic Development. Higher Education Close-Up 4, University of Cape Town, June.

Criticos, C. (1993). Experiential learning and critical learning for transformation and post-apartheid future. In Boud, D., Cohen, R and Walker, D. (Eds), Using Experience for Learning. Buckingham, UK: SRHE.

Cochran-Smith, M. \& Lytle, S. (1999). Relationships of knowledge and practice:

Teacher learning in communities' In Asghar Iran-Nejad and P. David Pearson (Eds). Review of Research in Education (pp. 249-303). Washington: American Educational Research Association.

Henning, E. (1999). Crafting a combinative ethnography of unlicensed teachers' journey towards professionalization. South African Journal of Higher Education, 13(3): 46-55.

McAlpine, L. and Weston, C. (2000). Reflection: Issues related to improving professors' teaching and students' learning. Instructional Science, 28: 363385.

McAlpine, L., Weston, C., Berthiaume, D., Fairbank-Roch, G \& Owen, M. (2004). Reflection on teaching: Types and goals of reflection. Educational Research and Evaluation, 337-363.

Letseka, M., Breier, M. and Visser, M. (2009). Poverty, race and student achievement in seven higher education institutions. In Letseka, M., Breier., M, Cosser M. and Visser, M. (Eds)Student Retention and Graduate Destination: Higher Education and Labour Market Access and Success (pp. 36 -54). Pretoria: HSRC Press. 
Muller, J. (2008). In search of coherence: A conceptual guide to curriculum planning in comprehensive universities. Report prepared for the SANTED Project, Centre for Education Policy Development

Nsibande, R. (2007) Using professional dialogue to facilitate meaningful reflection for Higher education practitioners. In Crisp,G., Hicks,M., Burdett, J., Gannaway, D., Maddox, L. and Winning, T. (Eds) Enhancing Higher Education, Theory and Scholarship (pp. 421-428). Proceedings of the $30^{\text {th }}$ HERDSA Annual Conference, Adelaide, 8-11 July.

Patton, M. Q. (2002). Qualitative Research and Evaluation Methods. London: SAGE.

Schön, D. A. (1987). Educating the Reflective Practitioner. San Francisco: JosseyBass.

Schön, D. A. (1995). The new scholarship requires a new epistemology. Change, 27, (6): 26- 34 .

Scott, I., Yeld, N., \& Hendry, J. (2007). Higher Education Monitor No. 6: A Case for Improving Teaching and Learning in South African Higher Education. Pretoria: Council on Higher Education.

Shulman, L. (1987). Knowledge and teaching: Foundations of the new reform. Harvard Educational Review, 57 (1): 1-22. 